\title{
Öğrenme Güçlüğü Olan ve Olmayan Öğrencilerin Sözel Problem Çözme ve Okuduğunu Anlama Becerileri Arasındaki İlişkiler*
}

\section{The Relationship Between Verbal Problem Solving and Reading Comprehension Skills of Student with and with-out Learning Disabilities}

\author{
Özlem Altındağ KUMAŞ**, Şenay Delimehmet DADA***, Ahmet YIKMIŞ****
}

Öz: Bu çalışmanın genel amacı, öğrenme güçlüğü olan/olmayan öğrencilerin okuduğunu anlama ve sözel problem çözme becerileri arasındaki ilişkileri ve okuduğunu anlama becerisinin sözel problem üzerindeki yordayıcıllğını incelemektir. Araştırmaya, Ankara ilinde bulunan 4. sınıfa devam 60 öğrenme güçlüğü olan, 60 normal gelişim gösteren öğrenci olmak üzere toplam 120 öğrenci dâhil edilmiştir. Çalışmada öğrenme güçlüğ̈̈ olan ve olmayan öğrencilerin okuduğunu anlama ve sözel işlem hesaplamalarındaki performansları $\mathrm{T}$ testi kullanılarak karşılaştırılmıştır. Öğrencilerin okuduğunu anlama ve sözel problemlerden elde ettikleri performanslar Basit Doğrusal Regresyon Analizi kullanılarak analiz edilmiştir. Elde edilen bulgular, okuduğunu anlamanın, sözel problem çözmenin önemli bir yordayıcısı olduğunu ortaya koymuştur. Ayrıca, öğrenme güçlüğü olan öğrencilerin, normal gelişim gösteren akranlarına göre okuduğunu anlamada daha düşük puan aldıkları, işlemleri daha uzun sürede tamamladıkları, daha az sayıda işlemi doğru çözdükleri görülmüştür.

Anahtar Kelimeler: Öğrenme gücüğü, okuduğunu anlama, sözel problemler, matematik güçlüğü

\begin{abstract}
The aim of this study is to examine the relationship between reading comprehension and verbal problem-solving skills of students with and without learning difficulties and to investigate the predictive skills of reading comprehension skills on verbal problem. The study group consisted of 120 fourth graders, 60 of whom had learning disabilities, 60 of whom normal development in Ankara. In the study, the performance of the students with and without learning disabilities were compared by using $\mathrm{T}$ test. The students' reading comprehension and verbal problems were analyzed using simple linear regression analysis. Findings revealed that reading comprehension was an important predictor of verbal problem solving. In addition, it was found that students with learning difficulties had lower scores in understanding reading than their peers who showed normal development, completed the procedures in a longer time and solved fewer procedures correctly.

Keywords: Learning difficulties, reading comprehension, verbal problems, math difficulties
\end{abstract}

\section{Giriş}

Öğrenme güçlügü, bireyin zekâsı normal veya normalin üzerinde olmasına rağmen yazılı ve sözlü dili anlama ve kullanmada, okuma-yazma, matematik gibi akademik becerilerde ortaya çıkan güçlükler olarak tanımlanmaktadır (American Psychiatric Association [DSM-V], 2013). Öğrenme güçlügü yaşayan öğrencilerin yaklaşık \%80'nin okuma sorunları yaşadıkları ve bu okuma sorunu yaşayan öğrencilerin de büyük bir kısmının matematik becerilerinde de güçlükler

\footnotetext{
* Bu çalışmanın bir kısmı II. Uluslararası Sosyal ve Beşerî Bilimler Berlin Konferansı'nda sözlü bildiri olarak sunulmuştur.

** Dr. Arş. Gör., Dicle Üniversitesi, Ziya Gökalp Eğitim Fakültesi, Diyarbakır - Türkiye, ORCID: 0000-0002-61042381, e-posta: ozlemmaltindag@gmail.com

*** Arş. Gör., Trabzon Üniversitesi, Fatih Eğitim Fakültesi, Trabzon - Türkiye, ORCID: 0000-0002-7412-5880, eposta: senaydm@gmail.com

**** Doç. Dr., Bolu Abant Izzet Baysal Üniversitesi, Eğitim Fakültesi, Bolu - Türkiye, ORCID: 0000-0002-1143-

1207, e-posta: yikmis_a@ibu.edu.tr
} 
yaşadıkları bildirilmektedir (Clements ve Sarama, 2007; Geary, Hoard ve Hamson, 2000; Jordan, Hanich ve Kaplan, 2003).

Öğrenme güçlüğü yaşayan öğrenciler üzerine yapılan çalışmalara bakıldığında ağırlıklı olarak dil, okuma ve yazma konuları üzerine yoğunlaştığı, matematik becerileri ile ilgili daha az çalışma yapıldığı görülmektedir (Al-Makahleh, 2011; Clements ve Sarama, 2014; Kinder, Kubina ve Marchnad, 2005; Osmon ve diğerleri, 2006). Yapılan bu araştırmalar sonucunda öğrenme güçlügü yaşayan öğrencilerin yaygın olarak sergiledikleri matematik güçlükleri aşağıda sıralanmıştır:

Zayıf hesaplama stratejileri: Matematiksel hesaplamalarda parmak sayma gibi gelişmemiş stratejilerin kullanılmasıdır (Jordan, Hanich ve Kaplan, 2003).

Kavramsal bilgi eksikliği: Bireyin sahip olduğu matematiksel bilgiyi, yeni bilgilerle bütünleştirememesidir (Fuchs, Fuchs ve Prentice, 2004).

Zayıf sayı bilgisi: Nicel sayıların (1, 2, 3 gibi), diğer unsurlara bağlı olarak değişmeyen kümeleri ifade ettiklerini anlamadaki yetersizliktir (Geary, Bow-Thomas ve Yao, 1992).

Otomatikleştirme yoksunluğu (İşlem hızı yavaşığı): Temel matematik işlemleri çözmedeki cevaplama süresinin uzamasıdır (Sousa, 2005).

Temel matematik işlem becerilerinde görülen yetersizlikler: Dört işlem becerileriyle ilgili matematiksel problemleri çözmek için gerekli olan kural ve işlemleri kullanmaktaki yetersizliktir (Ackerman ve Dykman, 1995; Bull ve Johnston, 1997).

Yukarıda sayılan matematik becerilerini öğrenmede zorluk çeken öğrenciler neredeyse her sınıfta görülebilmektedir. Yapılan araştırmalar, tüm okul kademelerindeki öğrencilerin $\% 5$ ile \%10'unun matematikte zorluk çektiğini ortaya koymuştur (Barbaresi, Katusic, Colligan, Weaver ve Jacobsen, 2005; Butterworth, Varma ve Laurillard, 2011; Rivera, 1997). Bu zorlukların motivasyon düşüklüğü, yetersiz strateji kullanımı, hafiza ve okuma becerilerinde güçlük gibi birçok olası nedeni vardır. Matematik becerilerinde güçlük yaşanan alanlarının başında sözel problemler gelmektedir. Sözel problemler, öğrenme güçlüğü yaşayan öğrencilerin de güçlük çektiği başlica alanlardan birisidir (Bryant, 2007). Sözel problemlerin çözülmesi için ögrencilerin gerekli bilişsel, dil ve okuma düzeyine sahip olmaları ve kendi kavramsal ve dilsel bilgi tabanını kullanarak dili işlemeleri ve soruyu yorumlamaları gerekmektedir (Englert ve diğerleri, 1987; Jitendra, 2007; Rivera, 1997).

Sözel problemlerde yaşanan güçlük nedenleri; problem cümlesini anlamama, okumaya odaklanamama, matematik ile ilgili terimleri anlamama, problemlerdeki bağlamı hayal edememe ve zayıf strateji kullanımıdır (Ballew ve Cunningham 1982; Bernardo 1999; Cooper ve Dunne 2000; Nunes, 1993) Matematik; işlemleri, sözel problemleri, kendine özgü sembolleri ve dili içerdiği için okuma ve matematik becerileri arasında güçlü bir ilişki bulunmaktadır (Ackerman ve Dykman, 1995; Hanich ve diğerleri, 2001; Jordan ve Hanich, 2000; Light ve DeFries, 1995; Miller ve Mercer, 1997; Rasanen ve Ahonen, 1995; Soylu ve Soylu, 2006; Ulu, Tertemiz ve Peker, 2016). Örneğin, Hanich ve diğerleri tarafindan yapılan çalışmada okuma becerileri iyi düzeyde olup sadece matematik güçlüğü (MG) yaşayan öğrenciler hem matematik hem okuma güçlüğü (OG) yaşayan öğrencilere göre sözel problemler becerilerinde daha iyi performans sergilemişlerdir. Ulu, Tertemiz ve Peker (2016) tarafından yapılan çalışmada, ilköğretim 5. sınıf öğrencilerinin sözel problemlerde yaptıkları hataları gidermeye ve öğrencilerin problem çözme başarısını artırmaya yönelik geliştirilen 22 saatlik çalışma sonucunda, okuduğunu anlama ve problem çözme stratejileri eğitimi alan deney grubunun, kontrol grubundan daha başarılı olduğu gözlenmiştir. Yapılan bazı boylamsal araştırmalarda da sınıf seviyesi artıkça, okuduğunu anlama becerilerinin problem çözme başarısı üzerindeki etkisinin artığ 1 bildirilmiştir (Anderson, 2010; Grimm, 2008). 
Sözel problem çözümü, öğrencilerin sadece sorunun doğru cevabını hesaplaması değil, aynı zamanda problem bilgisini anlama, yorumlama, sorunun zihinsel imgelerini oluşturma ve uygulanabilir bir çözüm yolu geliştirmeyi içermektedir (Bender, 2010; Montague, Warger ve Morgan, 2003; Shalev ve diğerleri, 2000). Örneğin, Shalev ve diğerleri tarafindan yapılan araştırmada anaokulu ve ilköğretim çă̆ındaki öğrencilerin okuduğunu anlama ile matematiksel becerileri arasında yüksek derecede bir ilişki bulunmuştur. Başka bir çalışmada çok basamaklı aritmetik işlem çözmenin üstbilişsel planlama gerektirmesi nedeniyle dil becerilerinin bu işlemlerde önemli bir rol üstlendiği bildirilmiştir (Bender, 2010). Jordan ve diğerleri (2002), iki yıllık boylamsal çalışmada, okuma güçlüğünün ileride ortaya çıkabilecek matematik güçlüğünü yordadığını bulmuşlardır. Genetik araştırmalarda da matematik ve okuma becerileri arasındaki ilişkinin orta ve yüksek düzeyde değişen oranlarla ilişkili olduğu ortaya çıkmıştır (Plomin ve Kovas, 2005).

Matematik güçlüğü yaşayan öğrencilerin okuma problemlerinin, problemlerdeki cümlelerin biçimsel ve yapısal özelliklerini anlayamamalarına, problemi doğru bir biçimde okuyamamalarına ve problem dilini anlayamamalarına neden olduğu ifade edilmektedir (Bender, 2010; Geary, 1993). Bu beceriler genellikle üst düzey düşünmeyi ve stratejik bir yaklaşımı gerektirir (Hudson ve Miller, 2006). Ballew ve Cunningham (1982), problemleri çözmede dört farklı beceriyi sınıflandırmış ve böylece öğrencilerin hangi becerilerde zorluk yaşadıklarının bulunabileceğini belirtmiş̧tir. Bu dört beceri:

(A) Sözel problemi okuma becerisi;

(B) Soruda hangi işlem becerilerinin kullanılacağını belirleme;

(C) Gerekli hesaplamayı yapabilme,

(D) Problemi yorumlama ve hesaplama becerileridir.

Bunlar göz önünde bulundurulduğunda, problem çözme sürecinin her aşamasının önceki aşamalara bağlı olduğu görülmektedir (Jitendra, 2007).

Dil, matematiksel terimler ile bunları anlayabilme arasındaki önemli bir bağlantıdır. $\mathrm{Bu}$ terimleri anlayabilmek için öğrencinin öncelikle okumanın temel hedefi olan okuduğunu anlamayı gerçekleştirmesi gerekmektedir. Snow, Burns ve Griffin'e (1998) göre okul öncesi yıllarda okuma becerilerinin niteliği matematik gibi akademik derslerdeki başarıyı da etkilemektedir. Araştırmacılar; okuduğunu anlamanın, matematiksel bilginin anlaşılmasında vazgeçilmez olduğunu vurgulamışlardır (Bowyer-Crane ve Snowling, 2005; Lindeman, 2000; Magliano, Trabasso ve Graesser, 1999). Matematiksel bilgiyi anlama ve çözümleyebilme, bilgiyi ilişkilendirip anlamlandırmaya yardımcı olacaktır. Dolayısıyla birey okumada başarılı bir temele sahipse bu onun matematik dilini sevebilmesini ve bu alanda başarılı olabilmesini sağlayacaktır. Matematiksel bilgiyi anlama, sadece metinlerin kavranmasını değil aynı zamanda bilimsel ve matematiksel işaretler, semboller ve grafikler, kod çözme ve anlama, farklı şekilde düzenlenmiş matematik metinlerini okuma ve farklı bir şekilde verilen bilgileri yorumlama becerisine sahip olmayı da gerektirmektedir (Barton, Heidema ve Jordan, 2002).

$\mathrm{Bu}$ araştırmada, sözel problem çözme ve okuma anlama becerileri arasındaki ilişki ve öğrenme güçlüğü olan ve olmayan öğrencilerin okuduğunu anlama becerilerinin sözel problem becerilerini nasıl etkilediği incelenmiştir. Türkiye' de öğrenme güçlügü olan öğrencilerle yapılan çalışmalara bakıldığında öğrencilerin matematik becerileri ile okuma becerileri arasındaki ilişkiyi inceleyen çalışmalara rastlanılmamıştır. Bu nedenle, bu çalışmanın alandaki boşluğu doldurarak ileride yapılacak çalışmalara temel oluşturacağı düşünülmektedir. Araştırmadan elde edilen bulgulardan yola çıkılarak öğrenme güçlüğü olan öğrencilerin hangi noktalarda güçlük yaşadıklarının belirlenmesi ile öğrencilerin matematiksel ve okuma becerilerine ilişkin performans düzeylerinin belirlenmesinde önemli katkı sağlayacağına inanılmaktadır. Matematik ve okuma becerilerinin, tüm akademik yaşam için önkoşul becerilerden biri olması nedeniyle öğrencilerin bu becerilerde ne gibi sinıllılıkları olduğunun, bunların nedenlerinin ve bu nedenlere ilişkin çözüm önerilerinin belirlenmesi şarttır. Araştırma sonuçlarının öğrenme güçlüğü risk grubunda olan çocukların erken dönem de desteklenmesi açısından da önemli bilgiler sağlayacağı düşünülmektedir. 


\title{
Yöntem
}

Bu bölümde araştırma deseni, çalışma grubu, veri toplama araçları, uygulama süreci ve verilerin analizine yer verilmiştir.

\begin{abstract}
Araştırma deseni
$\mathrm{Bu}$ araştırmada öğrenme güçlügü olan öğrencilerin matematik becerileri ve okuduğunu anlama becerilerinin normal gelişim gösteren akranlarınınkinden anlamlı olarak farklılaşıp farklılaşmadığı ve bu beceriler arasında ilişki olup olmadığının belirlenmesi amacıyla genel tarama modellerinden nedensel karşılaştırmalı model kullanılmıştır. (Büyüköztürk, Çakmak, Akgün, Karadeniz ve Demirel, 2016; Karasar, 2014).
\end{abstract}

\section{Çalışma grubu}

Araştırmanın çalışma grubunu, Ankara ilinde bulunan 60 ÖG (öğrenme güçlüğü) ve 60 NG (normal gelişim gösteren öğrenci) gösteren 4. sinıfa devam eden toplam 120 öğrenci oluşturmaktadır. Gruplar 2017-2018 eğitim öğretim yılında temel eğitime devam eden 4. sınıfta devlet okullarında öğrenim gören öğrenciler arasından seçilerek oluşturulmuştur. Öğrenme güçlügü grubunda yer alan öğrenciler, rehberlik araştırma merkezi tarafından tanısı konulmuş, öğrenme güçlüğü tanısı almış, ilköğretim okullarının kaynaştırma programlarına devam eden öğrenciler arasından seçilmişlerdir. ÖG grubundaki öğrencilerin 26'sını kız, 34'ünü erkek öğrenci, NG öğrencilerin 28'1 kız, 32'sini erkek öğrenci oluşturmaktadır. ÖG öğrencilerin yaş ortalaması 10 yaş 5 ay, NG öğrencilerin yaş ortalaması 10 yaş 8 aydır. ÖG grubunda yer alan öğrencilerin hepsi özel eğitim kurumlarına da devam etmektedirler. NG grubunda yer alan öğrenciler ise herhangi bir yetersizliği olmayan, öğretmen tarafından ortalama başarı düzeyine sahip olduğu belirtilen öğrenciler arasından seçilmiştir. NG grubunda yer alacak öğrenciler öğrenme güçlüğü olan öğrencilerle aynı sınıfa devam eden öğrencilerden oluşmuştur.

\section{Veri toplama araçları}

Formel Olmayan Okuma Envanteri (FOOE; Karasu, Girgin ve Uzuner, 2013): FOOE, birinci sınıftan sekizinci sınıfa kadar olan öğrencilerin okuduğunu anlama becerilerini değerlendirmek üzere Karasu, Girgin ve Uzuner (2013) tarafindan geliştirilmiş bir araçtır. İçerisinde 32 metin bulunan ve iki paralel formu bulunan testin içerisinde öyküleyici ve bilgilendirici metinler yer almaktadır. Bilgi verici metinler fen ve sosyal konularından seçilerek oluşturulmuştur. FOOE'de öğrencinin okuduğunu anlama becerisi öyküleyici metinler için; boşluk doldurma, okuma hatalarını kaydetme, okuduğunu anlatma ve soru sorma değerlendirme yöntemleri kullanılarak değerlendirilmekteyken bilgi verici metinler için okuduğunu anlatma ve soru sorma yöntemleri kullanılarak değerlendirilmektedir. Öğrencilerin okudukları öykülere dair anlatımlarını değerlendirmede her metin için; karakterler, ana olaylar ve detaylar olmak üzere üç bölümde puanlanan ve toplam 100 puan üzerinden değerlendirmeye olanak sağlayan okuduğun Anlatma değerlendirme formu kullanılmaktadır. Karakterlerin yer aldığı birinci bölüm 25 puandan oluşmakta, ana olayların yer aldığı ikinci bölüm 50 puandan oluşmakta ve son olarak detayların puanlandığı üçüncü bölüm ise 25 puandan oluşmaktadır. Bilgi verici metinlerde okuduğunu anlatmada, ana düşünce ve yardımcı düşüncelerden oluşan bölümler bulunmakta ve bu bölümler önem durumuna göre ayr1 ayrı puanlanarak toplam 100 puan üzerinden değerlendirilmektedir. Sorulara cevap verme formlarında da öykü ve bilgi verici metinlere ilişkin sorulan metinsel açık, metinsel kapalı ve bilgi ve deneyim bölümlerindeki sorular toplam 100 puan üzerinden değerlendirilmektedir. FOOE'de kapsam geçerliği, metin konularının öğrencilerin yaş, bilgi ve sınıf düzeylerine uygunluğu, öykü bölümlerinin tamlı̆̆ı, bilgi verici metin yapıları, metin konularının ve düzeylerinin denkliği, metinlerde kullanılan cümle yapıları ve sözcük çeşitleri, metinlerin okunabilirlik düzeyleri, soru çeşitleri, değerlendirme formlarının özellikleri gibi başlıklar altında uzman görüşü alınarak belirlenmiştir ve öğrencilerin okuma becerilerini değerlendirmede geçerli bir araç olduğu sonucuna ulaşılmıştır. Güvenirlik kapsamında ise farklı sınıf düzeylerindeki A ve B formlarından 8 öykü 
kullanılarak metinlerdeki öykü bölümlerinin tamlığına ilişkin güvenirlik hesaplanmıştır. Öykü bölümlerine ilişkin değerlendiriciler arası güvenirlik öykü düzeylerine göre \%94- \%100 aras1 olarak hesaplanmıştır. Bilgi verici metinlerde tüm metinlerin uygun yapılarda olup olmadığına ilişkin değerlendiriciler arası güvenirlik hesaplamaları yapılmıştır ve güvenirliğin .100 olduğu belirlenmiştir.

$\mathrm{Bu}$ araştırmada öğrencilerin okuduğunu anlama becerisini değerlendirmek amaciyla 4. düzeyde bulunan öyküleyici bir metin olan "İpek Ormanda" ile bilgilendirici bir metin olan ve bir fen konusu içeren "Çevremizdeki Varlıklar" metinleri kullanılmıştır.

Sözel Problem Soruları. Sözel problemler hazırlanmadan önce ilgili alanyazın gözden geçirilmiş Dickson, Brown ve Gibson (1984), Olkun ve Toluk Uçar, (2009) tarafindan belirtilen kategoriler göz önüne alınarak sorular hazırlanmıştır. Bu kategoriler aşağıdaki Tablo 1'de sunulmuştur:

Tablo 1.

Toplama ve Çıkarma İşlemi İçeren Sözel Problemler Kategorisi

\begin{tabular}{|c|c|c|c|}
\hline Toplama & \multicolumn{3}{|c|}{ Ç1karma } \\
\hline Birleștirme & Parça- Bütün & Ayırma & Karşılaştırma \\
\hline $\begin{array}{l}\text { Sonuç } \\
\text { Bilinmeyen } \\
(\mathrm{a}+\mathrm{b}=?)\end{array}$ & $\begin{array}{l}\text { Bütün } \\
\text { Bilinmeyen } \\
(a+b=?)\end{array}$ & $\begin{array}{l}\text { Sonuç } \\
\text { Bilinmeyen } \\
(\mathrm{a}-\mathrm{b}=?)\end{array}$ & $\begin{array}{l}\text { Fark Bilinmeyen } \\
(\mathrm{a}-\mathrm{b}=?)\end{array}$ \\
\hline $\begin{array}{l}\text { Değişim } \\
\text { Bilinmeyen } \\
(a+?=b)\end{array}$ & $\begin{array}{l}\text { Parça } \\
\text { Bilinmeyen } \\
(a+?=b)\end{array}$ & $\begin{array}{l}\text { Değişim } \\
\text { Bilinmeyen } \\
(\mathrm{a}-?=\mathrm{b})\end{array}$ & $\begin{array}{l}\text { Küçük Bilinmeyen } \\
(\mathrm{a}-?=\mathrm{b})\end{array}$ \\
\hline $\begin{array}{l}\text { Başlangiç } \\
\text { Bilinmeyen } \\
(?+\mathrm{a}=\mathrm{b})\end{array}$ & & $\begin{array}{l}\text { Başlangiç } \\
\text { Bilinmeyen } \\
(?-\mathrm{a}=\mathrm{b})\end{array}$ & $\begin{array}{l}\text { Büyük Bilinmeyen } \\
(?-\mathrm{a}=\mathrm{b})\end{array}$ \\
\hline
\end{tabular}

Sonraki aşamada ilkokul 4. sınıf MEB matematik programı incelenmiş ve yukarıdaki tablodaki kategoriler göz önüne alınarak her kategoriden bir soru olmak üzere 11 soru hazırlanmıştır. Hazırlanan soruların uygunluğu hakkında ortaokulda görev yapan beş matematik öğretmeninden uzman görüşü alınmıştır. Uzman görüşleri çerçevesinde gerekli düzenlemeler yapılarak sorular uygulama için hazır hale getirilmiştir. Sorular bir sayfaya dikey olarak yerleştirilmiş ve her bir sorunun çözümü için boşluklar bırakılmıştır.

\section{Uygulama}

Okuduğunu anlama aracının uygulanması sırasında 4. düzey bir öyküleyici metin (İpek Ormanda) ile bir bilgilendirici metin (Çevremizdeki Varlıklar) kullanılmıştır. Bu aracın uygulanması sırasında öğrenci ve uygulayıcı kopyası olmak üzere aynı metinleri içeren iki ayrı kitapçık hazır bulundurulmuştur. Kitapçığın öğrenci kopyasında metnin tam hali ve metinle ilgili sorular yer almıştır. Uygulayıcı kopyasında ise, metnin tam hali, okuduğunu Anlatma Formu ve metinle ilişkili sorular yer almıştır. Öyküleyici ve bilgilendirici metin için uygulama sıras1; öğrencinin metni sesli ve sessiz okuması, öğrencinin okuduğunu anlatması ve soruları cevaplamas1 şeklinde yürütülmüştür. Öğrenci metni okuduktan sonra, öğrencinin önündeki metin uygulamac1 tarafından kapatılarak öğrenciden okuduğunu anlatması istenmiştir. Uygulamacı değerlendirme formuna öğrencinin anlatımını kaydetmiş ve ses kaydı almıştır. Okuduğunu anlatma sırasında öğrenci zorlanırsa ve/veya yardım isterse, öğrencinin gerçek performansını görebilmek amacıyla, uygulamacı tarafindan herhangi bir yardım verilmemiştir ancak öğrenci hatırladığını anlatabilmesi için cesaretlendirilmiştir (Çok güzel anlatıyorsun, sonra ne olmuştu? , Olayı düşün, sonrasını hatırlamaya çalış" gibi). Okuduğunu anlatma sonrası metinle ilişkili soruların yanıtlanmasına geçilmiştir. Her bir soru uygulamacı tarafindan okunmuş ve öğrencinin de sözel olarak yanıt vermesi beklenmiştir. Öğretmen soruları okurken 
öğrenci de önündeki soruların yazılı olduğu öğrenci kopyasından takip etmiştir. Öğrencinin yanıtları herhangi bir düşünce ilavesi yapılmaksızın öğretmen kopyasına yazılmıştır. Öyküleyici metne ilişkin bu uygulamanın tamamlanmasının ardından bilgi verici metnin uygulamasına geçilmiştir. Bu aşamada da öyküleyici metinde olduğu gibi öğrenci ve öğretmen kopyaları kullanılmıştır. Bilgi verici metin uygulanmadan önce öğrenciye "Şimdi çevremizdeki varlıklar ile ilgili bir metin okuyacaksın. Sonra metinden anladığını anlatacaksın ve sorulara cevap vereceksin" şeklinde bir yönerge sunulmuştur. Sonrasında ise öğrenciye metni önce sesli okuması, ikinci kez okuduğunda ise isterse içinden okuyabileceği söylenmiştir. Okuma sonrası öğrencinin önündeki metin kapatılarak anladığını anlatması istenmiştir. Öğrencinin okuduğunu anlatmas1 öğretmen kopyasında yer alan okuduğunu anlatma değerlendirme formuna kaydedilmiştir. Ardından sorulara geçilip, uygulamacı tarafından sırasıyla okunan sorulara öğrencinin sözel yanıt vermesi beklenmiş ve verdiği yanıtlar uygulamacı kopyasına kaydedilmiştir.

Sözel problem soruları ile ilgili uygulamaya, başlamadan önce "Her bir soruya dikkatlice bak. Başla dediğim zaman ilk sorudan başla, her bir soruyu çözmeyi dene eğer sıradaki sorunun nasıl yapılacağını bilmiyorsan diğer soruya geç" yönergesi verilmiştir. Sorular öğrencilere okunmamıştır. Öğrencinin başlamasıyla birlikte araştırmacı kronometresini çalıştırmış ve ögrenci işlemleri tamamlayınca çalışma sonlandırılmıştır. Çalışma sonunda ögrencilerin yapmış olduğu her bir işlem analiz edilmiştir.

\section{Verilerin analizi}

Çalışmada ÖG ve NG gösteren öğrencilerin okuduğunu anlama ve sözel işlem hesaplamalarındaki performansları $\mathrm{T}$ testi kullanılarak karşılaştırılmıştır. Etki büyüklüklerinin değerlendirmesinde Green ve Salkind'in (2005) belirlemiş oldukları aralık noktaları dikkate alınmıştır. $\mathrm{Bu}$ aralıklar sırasıyla .01, (küçük), .06 (orta) ve .14 (büyük) olarak kabul edilmektedir. Uygulayıcı arası güvenirlik sağlanabilmesi için bütün veriler öğrencinin tanı bilgisine sahip olmayan bağımsız bir araştırmacı tarafindan tekrar değerlendirilerek görüş birliğine varılmıştır.

Bu çalışmada okuduğunu anlamanın ve sözel problemler üzerindeki yordayıcılı̆̆ının belirlenebilmesi Basit Doğrusal Regresyon Analizi uygulanmıştır. Analiz yapılmadan önce verilerin normal dağılıp dağılmadığı incelenmiştir. Normalliğe ilişkin, her iki değişken için skewness değerinin .68, kurtosis değerinin ise .42 olduğu görülmüş ve verilerin normal dağıldığ 1 varsayılmıştır (Tabachnick ve Fidell, 2001). Sonrasında regresyon analizine girecek olan değiş̧kenler arasında doğrusal bir ilişkinin olup olmadığına bakılmış, okuduğunu anlama ve sözel problemler değişkenleri için oluşturulan saçılma diyagramında noktaların bir eksen etrafında toplanma eğiliminde olduğu belirlenmiştir.

\section{Bulgular}

Araştırmada, okuduğunu anlamanın, sözel problemler üzerindeki yordayıcılığının belirlenebilmesinde Basit Doğrusal Regresyon Analiz uygulanmıştır ve analiz sonuçları Tablo 2'de özetlenmiştir. Araştırmaya katılan grupların dört işleme dayalı sözel problem çözmeye iliş̧kin puanları ise t- testi kullanılarak karşılaştırılmış ve analiz sonuçları Tablo 3'de gösterilmiştir.

Tablo 2.

Okuduğunu Anlamanın Sözel Problem Çözmeyi Açıklayıp Açıklamadığına İlişkin Basit Doğrusal Regresyon Analizi Sonuçları

\begin{tabular}{llccccc}
\hline Sözel Problem Çözme & $\mathrm{R}$ & $\mathrm{R}^{2}$ & $\mathrm{~F}$ & $\beta$ & $\mathrm{t}$ & $\mathrm{p}$ \\
\hline Okuduğunu Anlama & .56 & .31 & 26.63 & .56 & .00 & .00 \\
\hline
\end{tabular}

Regresyon analizi sonuçları incelendiğinde, okuduğunu anlamanın sözel problem çözmenin anlamlı bir yordayıcısı olduğu $\left(\mathrm{R}=.56, \mathrm{R}^{2}=.31, \mathrm{~F}=26.63, \mathrm{p}<.01\right)$ ve sözel problem 
çözme performansına ilişkin toplam varyansın \%31'nin okuduğunu anlama ile açıklandığı görülmektedir.

Tablo 3.

Öğrenme Güçlüğü Olan ve Olmayan Öğrencilerin Dört İşleme Dayalı Sözel Problem Çözmeye İlişkin T- Testi Sonuçları

\begin{tabular}{|c|c|c|c|c|c|c|c|}
\hline & Grup & $n$ & $\overline{\boldsymbol{x}}$ & ss & $F$ & $p$ & $\eta^{2}$ \\
\hline \multirow{2}{*}{ Okuduğunu anlama toplam puan } & ÖG & 60 & 39.41 & 21.10 & \multirow[b]{2}{*}{8.2} & \multirow[b]{2}{*}{.00} & \multirow[b]{2}{*}{.30} \\
\hline & NG & 60 & 65.72 & 15.19 & & & \\
\hline \multirow{2}{*}{ Problem hızı } & ÖG & 60 & 586.23 & 298.58 & \multirow[b]{2}{*}{127.77} & \multirow[b]{2}{*}{.00} & \multirow[b]{2}{*}{.22} \\
\hline & NG & 60 & 313.93 & 19.55 & & & \\
\hline \multirow{2}{*}{ Problem doğru sayısı } & ÖG & 60 & 2.10 & 1.59 & \multirow[b]{2}{*}{.54} & \multirow[b]{2}{*}{.00} & \multirow[b]{2}{*}{.90} \\
\hline & NG & 60 & 10.50 & .73 & & & \\
\hline \multirow{2}{*}{$\begin{array}{l}\text { Toplama işlemi gerektiren } \\
\text { sözel problemler* }\end{array}$} & ÖG & 60 & 5.56 & .92 & \multirow[b]{2}{*}{20.38} & \multirow[b]{2}{*}{.00} & \multirow[b]{2}{*}{.72} \\
\hline & NG & 60 & .50 & .73 & & & \\
\hline \multirow{2}{*}{$\begin{array}{l}\text { Çıkarma işlemi gerektiren } \\
\text { sözel problemler* }\end{array}$} & ÖG & 60 & 8.73 & 1.76 & \multirow[b]{2}{*}{.00} & \multirow[b]{2}{*}{.00} & \multirow[b]{2}{*}{.90} \\
\hline & NG & 60 & .50 & .73 & & & \\
\hline
\end{tabular}

*Bu değişkenlerde öğrencilerin yanlış sayısı göz önünde bulundurulmuştur.

Tablo 3'te gösterildiği gibi, tüm alt alanlarda gruplar arası farkl1lıkların .001 düzeyinde anlamlı olduğu görülmüştür. Gruplar arasındaki performans farklılıkları incelendiğinde ÖG yaşayan öğrenciler ile normal gelişim gösteren akranları arasındaki farklılıklarının çok yüksek olduğu, örneğin, problem doğru sayısına bakıldığında normal gelişim gösteren öğrencilerin ortalama doğru problem sayıs1 10.50 iken, öğrenme güçlüğü yaşayan öğrencilerin doğru sayıs1 ortalama 2.1 olduğu bulunmuştur. Gruplar arasındaki farka ilişkin etki büyüklüklerinin ise tüm alt alanlarda oldukça yüksek (.22 - .90) olduğu görülmüştür. En yüksek etki büyüklüğünün problem doğru sayısı ve çıkarma işlemi gerektiren sözel problemler alt alanlarında $(\eta 2=.90)$ olduğu dikkat çekmiştir.

\section{Tartışma ve Sonuç}

$\mathrm{Bu}$ çalışmada öğrenme güçlüğü olan ve olmayan temel eğitime devem eden 4 . sınıf öğrencilerinin okuduğunu anlama becerileri ile sözel problem çözme becerileri arasındaki ilişkilere bakılmış ve okuduğunu anlama becerisinin sözel problem çözme üzerindeki yordayıcılığı incelenmiştir. Sonuçlar, okuduğunu anlamanın, sözel problem çözmenin önemli bir yordayıcısı olduğunu ortaya koymuştur. Ayrıca, öğrenme güçlügü olan öğrencilerin, normal gelişim gösteren akranlarına göre okuduğunu anlamada daha düşük puan aldıkları, işlemleri daha uzun sürede tamamladıkları, daha az sayıda işlemi doğru çözdükleri görülmüştür. Öğrenme güçlüğü olan öğrencilerin normal gelişim gösteren öğrencilere göre okuduğunu anlama ve sözel problemlerde düşük performans göstermesi şaşırtıcı bir sonuç değildir (Baydık, Ergül ve Bahap Kudret, 2012; Gökçe-Sarıpınar ve Erden, 2010; Fuchs ve diğerleri, 2010; Karaman, Türkbay ve Gökçe, 2006; Swanson, Jerman ve Zheng, 2008). Araştırmadaki şaşırtıc1 sonuçlardan birisi öğrenme güçlüğü olan öğrencilerin nerdeyse tamamının toplama ve çıkarma işlemi gerektiren tek aşamada çözülebilen soruları yanlış çözmesidir. Araştırmaya katılan öğrenme güçlüğü olan öğrenciler ilköğretim okullarının kaynaştırma programlarına devam eden ve öğretmenleri tarafından bireyselleştirilmiş eğitim programı uygulandıkları belirtilen ve özel eğitim kurumlarına devam eden öğrenciler arasından seçilmişlerdir. Bu durum bu öğrencilere yapılan müdahalelerin yetersiz olduğunu göstermektedir. Dolayısıyla bu öğrencilerin yaşadıkları güçlükleri en aza indirmede öğrencilerin güçlükleri konusunda öğretmenlerin farkındalıklarının arttırılması, sözel problem çözme, dört işlem becerileri ve okuduğunu anlamayı geliştirmeye 
yönelik müdahaleler konusunda öğretmenlerin bilgilendirilmeleri ve uygulamaya aktarmaları konusunda desteklenmeleri önemlidir.

Araştırmanın diğer bir sonucunda çalışmaya dâhil edilen öğrencilerin okuduğunu anlama performanslarının \%31'inin onların sözel problem çözme becerileri ile açıklanabileceği sonucuna ulaşılmıştır. Bu sonucun ilgili alanyazın ile tutarlı olduğu görülmektedir (Bender, 2010; Montague, 2003; Sertöz, 2003; Shalev ve diğerleri, 2000). Temel eğitim yıllarında edinilen okuduğunu anlama becerisi öğrencinin yaşamı boyunca tüm öğrenmelerini ve akademik becerilerini etkilemektedir (Göktaş ve Gürbüztürk, 2012). Dolayısıyla çalışmadan elde edilen bu sonucun okuduğunu anlama becerisinde yaşanabilecek güçlükleri önceden belirlemek ve buna yönelik müdahaleler kullanılması açısından önemli olduğu düşünülmektedir. Ayrıca, bu becerilerin erken dönemde değerlendirmesi, çocukların ileriki dönemlerde yaşayabilecekleri akademik güçlüklerin önüne geçilmesini sağlayacaktır. Matematik performansını okuduğunu anlamayı etkileyen tüm becerilerinden (örneğin, kod çözme ve anlama, sözcük bilgisi, sesbilgisel farkındalık) etkilenmektedir (Fuchs ve diğerleri, 2010). Dolayısıyla, ÖG olan öğrencilerin okuduğunu anlamadaki diğer süreçlerin de desteklenmesi gerektiği açıktır. $\mathrm{Bu}$ nedenle, okuduğunu anlamanın bileşenlerinin incelenerek öğretim programlarının içerisine dâhil edilmesi ve öğretmenlerin uygulama konusunda desteklenmelerinin önemli olduğu düşünülmektedir. Sonuç olarak okuduğunu anlamanın, sözel problem çözmede ön koşul beceri olduğu ve okuduğunu anlama becerisinin geliştirilmesinin çocukların ileride sözel problem çözmede güçlük yaşamaması için önemli olduğu görülmüştür.

Matematik ve okumada yaşanan güçlüklerin sonraki yıllarda da artarak devam ettiği ve bu durumun öğrencilerin motivasyonlarını etkileyerek derse karşı ilgisizliğe, yeni şeyler denemekten kaçınmaya ve bazı durumlarda okulu terk etmeyle bile sonuçlandığı görülmektedir (Deshler, Ellis ve Lenz, 1996; Glago ve diğerleri, 2009; Miller, Butler ve Lee, 1998). Dolayısıyla, bu alanlarda güçlük yaşayan öğrencilerin belirlenmesi, öğrencilerin gereksinim duyduğu alanlarda desteklenmesi, öğretmenlerin ise öğrencilerin bireysel gereksinimlerini karşılayacak şekilde öğretimi planlamaları ve gerekli uyarlamaları yapmaları önemlidir. Ayrıca erken çocukluk döneminden başlayarak bu öğrencilerin okuma becerilerini geliştirmenin yanında matematik becerilerinin de izlenmesi ve geliştirilmesi önem taşımaktadır. Okuma ve matematik becerileri gibi karmaşık bilişsel süreçlere ait yetersizlikleri anlamak, çocukların potansiyellerine ulaşmalarına yardımcı olmada önemli bir araçtır (Butterworth ve Kovas, 2013).

Son olarak, bu çalışmanın birtakım sınırlılıkları bulunmaktadır. Çalışmada öğrencilerin sözel problem ve okuduğunu anlama becerilerine ilişkin elde edilen tüm veriler, değerlendirmelerin yapıldığ 1 değerlendirme araçları ile sınırlıdır. Bu nedenle bundan sonraki çalışmalarda farklı değerlendirme araçlarıyla değerlendirilmesi ile elde edilen bulguların genellenebilirliğinin artacağı düşünülmektedir. Çalışmada kullanılan sözel problemlerin, öğrencilerinin kendisinin okuyup çözmesi istenmiştir, benzer soruların öğrencilere okunup çözülmesinin de sağlanması okuduğunu anlamanın sözel problemler üzerindeki etkisini daha net ortaya koyacaktır. Bu çalışmada sadece temel eğitime devam eden 4. sınıf öğrencileri ile çalışılmıştır. $\mathrm{Bu}$ nedenle, gelecek çalışmalarda farklı sınıf düzeyindeki öğrencilerin de okuduğunu anlama ve sözel problem çözme performanslarının karşılaştırılması önerilmektedir. Çalışmada yetersizlik gruplarından sadece öğrenme güçlüğü olan öğrencilerin performansları incelenmiştir. Gelecek araştırmalarda diğer yetersizlik gruplarında yer alan öğrencilerin performanslarının incelenmesi ve yaşadıkları güçlüklerin belirlenmesi önemlidir.

\section{Kaynaklar}

Ackerman, P. T., Anhalt, J. M. ve Dykman, R. A. (1986). Arithmetic automation failure in children with attention and reading disorders: Associations and sequela. Journal of Learning Disabilities, 19(4), 222-232.

Al-Makahleh, A. A. (2011). The effect of direct instruction strategy on math achievement of primary 4th and 5th grade students with learning difficulties. International Education Studies, 4(4), 199-205. 
American Psychiatric Association. (2013). Diagnostic and statistical manual of mental disorders (5th ed.). Arlington, VA: American Psychiatric Publishing.

Anderson, U. (2010). Skill development in different components of arithmetic and basic cognitive functions: Findings from a 3-year longitudinal study of children with different types of learning difficulties. Journal of Educational Psychology, 102(1), 115-134.

Ballew, H. ve Cunningham, J. (1982). Diagnosing strengths and weaknesses of sixth-grade students in solving word problems. Journal for Research in Mathematics Education, 13(3), 202-210.

Barbaresi, W. J., Katusic, S. K., Colligan, R. C., Weaver, A. L. ve Jacobsen, S. J. (2005). Math learning disorder: Incidence in a population-based birth cohort, 1976-82, Rochester, Minn. Ambulatory Pediatrics, 5(5), 281-289.

Barton M. L., Heidema, C. ve Jordan, D. (2002). Teaching reading in mathematics and science. Educational Leadership, 60(3), 24-28.

Baydık, B., Ergül, C. ve Kudret, Z. (2012). Okuma güçlüğü olan öğrencilerin okuma akıcılığı sorunları ve öğretmenlerinin bu sorunlara yönelik öğretim uygulamaları. [Reading fluency problems of students with reading difficulties and teaching practices of teachers about these problems]. Illkögretim Online, 11(3), 778-789.

Bender, W. N. (2010). Learning disabilities: Characteristics, identification, and teaching strategies (6th Ed.). Boston: Pearson/Allyn and Bacon.

Bernardo, A. 1999. Overcoming obstacles to understanding and solving word problems in mathematics. Educational Psychology, 19(2), 149-163.

Bowyer-Crane, C. ve Snowling, M. J. (2005). Assessing children's inference generation: What do tests of reading comprehension measure? British Journal of Educational Psychology, $75,189-201$.

Bull, R. ve Johnston, R. S. (1997). Children's arithmetical difficulties: Contributions from processing speed, item identification, and short-term memory. Journal of Experimental Child Psychology, 65, 1-24.

Butterworth, B., Varma, S. ve Laurillard, D. (2011). Dyscalculia: from brain to education. Science, 332(6033), 1049-1053.

Butterworth, B. ve Kovas, Y. (2013). Understanding neurocognicve developmental disorders can improve educacon for all. Science, 340(6130), 300-305.

Büyüköztürk, Ş., Çakmak, E., Akgün, Ö. E., Karadeniz, Ş. ve Demirel, F. (2016). Bilimsel araştırma yöntemleri. [Scientific research methods]. (17. Bask1). Ankara: Pegem Yayınları.

Clements, D. H. ve Sarama, J. (2007). Effects of a preschool mathematics curriculum: Summative research on the Building Blocks project. Journal for Research in Mathematics Education, 38, 136-163.

Cooper, B. ve Dunne, M. 2000. Assessing children's mathematical knowledge: social class, sex and problem-solving. Buckingham: Open University Press.

Correa, J., Nunes, T. ve Bryant, P. (1998). Young children's understanding of division: the relationship between division terms in a noncomputational task. Journal of Educational Psychology, 90(2), 321-329

DeCorte, E. ve Verschaffel, L. (1987). The effect of semantic structure of first-graders' strategies for solving addition and subtraction word problems. Journal for Research in Mathematics Education, 18, 363-381.

Deshler, D. D., Ellis, E. S. ve Lenz, B. K. (1996). Teaching adolescents with learning disabilities: Strategies and Methods (2nd ed.). Denver, CO: Love.

Dickson, L., Brown, M. ve Gibson, O. (1984). Children learning mathematics. Eastbourne, East Sussex: Holt, Rinehart and Winston.

Engelhardt, J. M. (1977). Analysis of children's computational errors: A qualitative approach. British Journal of Educational Psychology, 47, 149-154.

Ergül, C. (2012). Okumada güçlük yaşayan öğrencilerin okuma performanslarının öğrenme güçlügü riski açısından değerlendirilmesi. [Evaluation of reading performance of 
students with difficulty in reading in terms of learning disability risk]. Kuram ve Uygulamada Eğitim Bilimleri, 12(3), 2033-2057.

Fuchs, L. S. ve Fuchs, D. (2002). Mathematical problem-solving profiles of students with mathematics disabilities with and without comorbid reading disabilities. Journal of Learning Disabilities, 35, 563-573.

Fuchs, L. S., Fuchs, D. ve Prentice, D. (2004). Responsiveness to mathematical problem-solving instruction: Comparing students at risk of mathematics disability with and without risk of reading disability. Journal of Learning Disabilities, 37(4), 293-306.

Fuchs, L. S., Powell, S. R., Seethaler, P. M., Cirino, P. T., Fletcher, J. M., Fuchs, D., et al (2010). The effects of strategic counting instruction, with and without deliberate practice, on number combination skill among students with mathematics difficulties. Learning and Individual Differences, 20, 89-100.

Geary, D. C., Bow-Thomas, C. C. ve Yao, Y. (1992). Counting knowledge and skill in cognitive addition: A comparison of normal and mathematically disabled children. Journal of Experimental Child Psychology, 54, 372-391.

Geary, D. G. (1993). Mathematical disabilities: Cognitive, neuro-psychological, and genetic components. Psychological Bulletin, 114, 345-362.

Geary, D. C., Hoard, M. K. ve Hamson, C. O. (1999). Numerical and arithmetical cognition: Patterns of functions and deficits in children at risk for a mathematical disability. Journal of Experimental Child Psychology, 74, 213-239.

Glago, K., Mastropieri, M. A. ve Scruggs, T. E. (2009). Improving problem solving of elementary students with mild learning disabilities. Remedial and Special Education, 30(6), 372-380.

Gökçe-Sarıpınar, E. ve Erden, G. (2010). Okuma güçlüğünde akademik beceri ve duyusal-motor işlevleri değerlendirme testlerinin kullanılabilirliği. [The availability of academic skills and sensory-motor functions assessment tests in reading difficulties]. Türk Psikoloji Dergisi, 25(65), 56-66.

Göktaş, Ö. ve Gürbüztürk, O. (2012). Okuduğunu anlama becerisinin ilköğretim ikinci kademe matematik dersindeki akademik başarıya etkisi. [The effect of reading comprehension on academic achievement in primary school mathematics course]. Uluslararası Eğitim Programları ve Öğretim Çalışmaları Dergisi (IJOCIS),4(2), 52-66

Green, S. B. ve Salkind, N. J. (2005). Using SPSS for Windows and Macintosh: Analyzing and understanding data. Upper Saddle River, NJ: Pearson/Prentice Hall.

Grimm, K. J. (2008). Longitudinal associations between reading and mathematics. Developmental Neuropsychology, 33(3), 410-426.

Hanich, B. H., Jordan, N. C., Kaplan, D. ve Dick, J. (2001). Performance across different areas of mathematical cognition in children with learning difficulties. American Psychological Association, 93(3), 615-626. DOI: 10.1037//0022- 0663.93.3.615

Hudson, P. ve Miller, S. P. (2006). Designing and implementing mathematics instruction for students with diverse learning needs. Boston, MA: Allyn \& Bacon

Jordan, N. C. ve Hanich, L. B. (2000). Mathematical thinking in second grade children with different forms of LD. Journal of Learning Disabilities, 33, 567-578.

Jordan, N. C., Hanich, L. B. ve Kaplan, D. (2003). Arithmetic fact mastery in young children: A longitudinal investigation. Journal of Experimental Child Psychology, 85, 103-119.

Jitendra, A. K. (2007). Solving math word problems: Teaching students with learning disabilities using schema-based instruction. Austin, TX: Pro-Ed.

Karaman, D., Türkbay, T. ve Gökçe, F. S. (2006). Özgül öğrenme bozukluğu ve dikkat eksikliği hiperaktivite bozukluğu binişikliğinin bilişsel özellikleri. [Cognitive characteristics of specific learning disorder and attention deficit hyperactivity disorder]. Çocuk ve Ruh Sağglı̆̆ Dergisi, 13, 2, 60-68.

Karasar, N. (2014). Bilimsel araştırma yöntemi. [Scientific research method]. (26. Baskı). Ankara: Nobel Yayın Dağıtım. 
Kinder. D., Kubina, R. ve Marchand-martella, N. (2005). Special education and direct instruction: An effective combination. Journal of Direct Instruction, 5(1), 1-36.

Lindeman, J. (2000). ALLU Ala-Asteen Lukutesti: Tekniset tiedot [ALLU Reading Test for Primary School: Technical Information]. Turku, Finland: University of Turku Centre for Research on Learning.

Light, J. G. ve DeFries, J. C. (1995). Comorbidity of reading and mathematics disabilities: Genetic and environmental etiologies, Journal of Learning Disabilities 28, 96-106.

Magliano, J., Trabasso, T. ve Graesser, A. C. (1999). Strategic processing during comprehension. Journal of Educational Psychology, 91, 615-630.

Montague, M. (2003). Solve it! A practical approach to teaching mathematical problem solving skills. Reston, VA: Exceptional Innovations

Miller, S. P., Butler, F. M. ve Lee, K. (1998). Validated practices for teaching mathematics to students with learning disabilities: A Review of Literature. Focus on Exceptional Children, 31(1), 1-24.

Miller, S. P. ve Mercer, C. D. (1997). Educational aspects of mathematics disabilities. Journal of Learning Disabilities, 30, 47-56.

Nunes, T., Schliemann, A. D. ve Carraher, D. W. (1993). Mathematics in the streets and in schools. Cambridge: Cambridge University Press.

Olkun, S. ve Toluk, Z. (2009). Illkögrretimde etkinlik temelli matematik ögretimi. [Activity based mathematics teaching in primary education]. Ankara: An1 Yayınc1lı, Ertem Matbaacilik.

Osmon, D., Smerz, J., Braun, M. ve Plambeck, E. (2006). Processing abilities associated with math skills in adult learning disability. Journal of Clinical and Experimental Neuropsychology, 28, 84-95.

Plomin, R. ve Kovas, M. (2005). Generalist genes and learning disabilities. Psychological Bulletin, 131, 592-617.

Rasanen, P. ve Ahonen, T. (1995). Arithmetic disabilities with and without reading difficulties: A comparison of arithmetic errors. Developmental Neuropsychology, 11, 275-295.

Rivera, D. P. (1997). Mathematics education and students with learning disabilities: Introduction to the special series. Journal of Learning Disabilities, 30, 2-19.

Sertöz, T. (2003). Illköğretim okullarının 6. sinuflarında okuduğunu anlama davranışının kazandırılmasinın matematik başarısina etkisi. [The effect of reading comprehension behavior in the 6th grade of primary schools on the mathematics achievement]. (Yayımlanmamış yüksek lisans tezi). Marmara Üniversitesi Eğitim Bilimleri Enstitüsü, İstanbul.

Shalev R. S., Auerbach, J., Manor, O. ve Gross Tsur, V. (2000). Developmental dyscalculia: Prevalence and prognosis. European Child and Adolescent Psychiatry, 9, 58-64.

Snow, C. E., Burns, M. S. ve Griffin, P. (Eds.) (1998). Preventing reading difficulties in young children. Washington, DC: National Academy Press,

Soylu, Y. ve Soylu, C. (2006). Matematik derslerinde başarıya giden yolda problem çözmenin rolü. [The role of problem solving in mathematics]. İnönü Üniversitesi Eğitim Fakültesi Dergisi, 7, 97-111.

Swanson, H. L., Jerman O. ve Zheng, X. (2008). Growth in working memory and mathematical problem solving in children at risk and not at risk for serious math difficulties. Journal Education Psychology, 100, 343-379.

Tabachnick, B. G. ve Fidell, L. S. (2001). Using multivariate statistics (4th ed.). Needham Heights, MA: Allyn \& Bacon.

Ulu, M., Tertemiz, N. ve Perker, M. (2016). Okuduğunu anlama ve problem çözme stratejileri eğitiminin ilköğretim 5. sınıf öğrencilerinin rutin olmayan problem çözme başarısına etkisi. [The effect of reading comprehension and problem solving strategies education on the non-routine problem solving success of 5th grade students]. Afyon Kocatepe Üniversitesi Sosyal Bilimler Dergisi, 18(2), 303-340. 
Van Luit, J. E. H. ve Naglieri, J. A. (1999). Effectiveness of the MASTER strategy training program for teaching special children multiplication and division. Journal of Learning Disabilities, 32, 98-107.

Zheung, X., Flynn, L. J. ve Swanson, H. L (2012). Experimental intervention studies on word problem solving and math disabilities: A selective analysis of the literature. Learning Disability Quarterly, 36(2), 97-111.

\section{Extended Abstract}

\section{Introduction}

In this study, the relationship between verbal problem solving and reading comprehension skills and how students with and without learning disabilities have an effect on their verbal problem skills. In addition, the effects of reading comprehension skills on verbal problem skills were investigated. In Turkey, there is no study that examined the relationship between reading skills and math skills of students with learning difficulties. Therefore, this study is thought to be the basis for future studies by filling the gap in the literature. The research will contribute to the determination of students 'difficulty in learning difficulties and to determine the students' performance levels in mathematical and reading skills. As mathematics and reading skills are one of the prerequisite skills for all academic life, it is necessary to determine the limitations of the students on these skills and their reasons and their solution suggestions for these reasons should be determined. It is thought that the results of the research will provide important information for the children who are in the learning disability risk group.

\section{Method}

Relational screening model was used in this study to compare groups' performances in verbal problem solving and reading comprehension. The study group consisted of 120 fourth graders, 60 of whom had learning disabilities, 60 of whom normal development in Ankara.

In this study, the performance of students with learning disabilities and normal development in reading comprehension and verbal processing calculations were compared by using T test. Green and Salkind (2005) determined the gap points in the evaluation of impact sizes. These ranges are .01, (small), .06 (medium) and .14 (large) respectively. In this study, simple linear regression analysis was applied to determine the predictive and predictive of verbal problems.

\section{Discussion and Conclusion}

In this study, the relationship between reading comprehension skills and verbal problem-solving skills of 4th grade students with learning disabilities and without learning difficulties was examined and the predictive ability of reading comprehension skills on verbal problem solving was examined. The results revealed that reading comprehension is an important predictor of verbal problem solving. In addition, it was found that students with learning difficulties had lower scores in understanding reading than their peers who showed normal development, completed the procedures in a longer time and solved fewer procedures correctly.

It is not surprising that students with learning disabilities show poor performance in reading comprehension and verbal problems compared to normal development students (Baydık, Ergül \& Bahap Kudret, 2012; Gökçe-Sarıpınar \& Erden, 2010; Karaman, Türkbay \& Gökçe, 2006; Swanson, Jerman \& Zheng, 2008).

One of the surprising results of the research is that almost all of the students with learning difficulties solve the questions that can be solved in a single stage which requires addition and subtraction. The students with learning disabilities were selected from among the students attending the mainstreaming programs of elementary schools and continuing their special education institutions. This shows that the interventions to these students are insufficient. Therefore, it is important that these students are encouraged to increase the awareness of teachers about their difficulties in minimizing the difficulties experienced by 
students, to inform and implement teachers about verbal problem solving, four processing skills and interventions to improve reading comprehension

As a result of the study, it was concluded that $31 \%$ of the reading comprehension performances of the students included in the study can be explained by their verbal problem solving skills. This result appears to be consistent with the relevant literature (Bender, 2010; Montague, 2003; Sertöz, 2003). Reading comprehension skills acquired during basic education years affect the student's learning and academic skills throughout his life (Göktaş \& Gürbüztürk, 2012). Therefore, it is thought that this result obtained from the study is important in terms of determining the difficulties in reading comprehension skills and using the interventions for this. In addition, early evaluation of these skills will help to prevent academic difficulties that children may experience in the future. It is influenced by all the skills (eg, decoding and comprehension, vocabulary, phonological awareness) that affect understanding of reading math performance (Fuchs et al., 2010). Therefore, it is obvious that other processes in reading comprehension should be supported. For this reason, it is considered that it is important to include the components of reading comprehension into the curriculum and to support the teachers in implementation. As a result, it is seen that reading comprehension is a prerequisite skill in verbal problem solving and improving reading comprehension skills is important for children to have difficulty in verbal problem solving in the future. 